\title{
RETRACTION NOTE
}

https://doi.org/10.1038/s41586-018-0311-z

\section{Retraction Note: DDX5 and its associated lncRNA Rmrp modulate $\mathrm{T}_{\mathrm{H}} 17$ cell effector functions}

Wendy Huang, Benjamin Thomas, Ryan A. Flynn,

Samuel J. Gavzy, Lin Wu, Sangwon V. Kim, Jason A. Hall, Emily R. Miraldi, Charles P. Ng, Frank Rigo, Sarah Meadows, Nina R. Montoya, Natalia G. Herrera, Ana I. Domingos, Fraydoon Rastinejad, Richard M. Myers, Frances V. Fuller-Pace, Richard Bonneau, Howard Y. Chang, Oreste Acuto \& Dan R. Littman

Retraction to: Nature https://doi.org/10.1038/nature16193, published online 16 December 2015; corrected 20 January 2016.

In follow-up experiments to this Article, we have been unable to replicate key aspects of the original results. Most importantly, an RNA-dependent physical association of ROR $\gamma$ t and DDX5 cannot be reproduced and is not substantiated upon further analysis of the original data. The authors therefore wish to retract the Article. We deeply regret this error and apologize to our scientific colleagues. Dan R. Littman, Benjamin Thomas, Ryan A. Flynn, Samuel J. Gavzy, Lin Wu, Sangwon V. Kim, Jason A. Hall, Emily R. Miraldi, Charles P. Ng, Frank Rigo, Sarah Meadows, Nina R. Montoya, Natalia G. Herrera, Ana I. Domingos, Fraydoon Rastinejad, Richard M. Myers, Frances V. FullerPace, Richard Bonneau, Howard Y. Chang and Oreste Acuto agree to the Retraction. Wendy Huang declined to sign the Retraction letter. 